\title{
Analisa Aplikasi Teknologi Informasi dan Strategi Bisnis Perusahaan Agrobisnis
}

\author{
Buhori Muslim ${ }^{1}$, Debi Gusmaliza ${ }^{2}$, Sasmita ${ }^{3}$ \\ ${ }^{1}$ Universitas Putra Indonesia (UNPI) Cianjur; Jl. Dr. Muwardi No.66, By Pass Cianjur 43215 \\ ${ }^{23}$ Sekolah Tinggi Teknologi Pagaralam; Jl. M. Siagim No. 75 Karang Dalo, Telp/Fax (0730) \\ 621916 \\ ${ }^{123}$ Program Studi Teknik Informatika \\ Email: 'buhoristtp@gmail.com, 2debigusmaliza13@gmail.com, 33sasmitha@gmail.com.
}

\begin{abstract}
Abstrak
Menjalankan usaha memerlukan strategi yang tepat agar usaha berjalan dengan baik dan menguntungkan, strategi bisnis khusus, aplikasi teknologi dan sistem informasi (TSI) menjadi penunjang yang paling diharapkan dan menjadi solusi. Indonesia dan Kota Pagar Alam khususnya wilayahnya merupakan daerah pertanian, saat ini di Pagar alam bisnis pertanian dikelola dengan efisien secara agrobisnis, objek penelitian merupakan gabungan Perusahaan agrobisnis jeruk, agrobisnis salak, agrobisnis alpokat dan sebagainya. Adapun dari penelitiah ini telah dihasilkan kondisi internal dan eksternal perusahaan agrobisnis, dari sisi bisnis maupun teknologi dan sistem informasi (TSI), langkah selanjutnya dilaksanakan evaluasi dan pemberian rekomendasi strategi pengembangan bisnis yang sesuai dengan kebiasaan perusahaan agrobisnis. Dimana usulan strategis yang dihasilkan penelitian ini mencakup teknologi dan sistem informasi berupa usulan berbentuk elektronik (pemanfaatan cloud computing) serta portofolio aplikasi teknologi dan administrative yang mampu mendukung pelaksanaan proses bisnis perusahaan agrobisnis. Untuk strategi manajemen Teknologi dan sistem informasinya berupa list usulan jenis kegiatan bisnis yang bisa meningkatkan kesesuaian dan kematangan strategi bisnis perusahaan agrobisnis.
\end{abstract}

Kata kunci - Strategi, daerah, perisahaan, agrobisnis, elektronik, usulan.

\begin{abstract}
Running a business requires the right strategy so that the business runs well and is profitable, specific business strategies, technology applications and information systems (TSI) are the most expected support and become a solution. Indonesia and Pagar Alam City in particular are agricultural areas, currently in Pagar Alam the agricultural business is managed efficiently in an agribusiness manner, the object of research is a combination of citrus agribusiness companies, zalacca agribusinesses, avocado agribusinesses and so on. From this research, the internal and external conditions of agribusiness companies have been generated, in terms of business and technologyand information systems (TSI), the next step is to evaluate and provide recommendations for business development strategies in accordance with the habits of agribusiness companies. Where the strategic proposals produced by this study include technology and information systems in the form of electronic proposals (the use of cloud computing) as well as a portfolio of technology and administrative applications that are able to support the implementation of agribusiness company business processes. For technology management strategies and information systems in the form of a list of proposed types of business activities that can increase the suitability and maturity of agribusiness company business strategies.
\end{abstract}

Keywords - Strategies, regions, companies, agribusiness, electronics, proposals. 


\section{PENDAHULUAN}

Pada saat ini perkembangan aplikasi teknologi dan sistem informasi (TSI) sangat luar biasa, serta sangat berperan dalam mendukung berbagai aplikasi yang menyokong kehidupan [1], tentu teknologi internet yang paling utama, melalui observasi CIPG (center of innovation policy and governance), sebuah instansi riset yang bergerak pada studi terhadap inovasi, kebijakan, dan tata kelola. Telah dihasilkan hasil survey yang dirilis pada 2018 menyatakan bahwa pengguna teknologi internet di Indonesia tahun 2016 mencapai 132,7 juta orang dengan angka proyeksi penduduk 2017 sekitar 261,89 juta jiwa, ini membuktikan bahwa penetrasi internet di Indonesia sangat tinggi, bila dibandingkan jumlah penduduk asia maka jumlah ini menjadi yang paling banyak [2]. Hal ini terjadi karena teknologi internet disadari sangat bermanfaat sebagai sarana penunjang berkomunikasi dan berinteraksi dengan cepat di seluruh wilayah Indonesia yang luas [3], paling utama teknologi TSI (Internet) paling berperan terhadap perubahan dan pergeseran gaya hidup masyarakat perkotaan, karena berbagai kemudahan yang ditawarkannya melalui proses digitalisasi pada berbagai aspek persoalan hidup, ini yang ditawarkan para creator dalam menciptakan kreasi dan solusi atas persoalan melalui inovasi teknologi, tingginya penetrasi teknologi berbasis internet di Indonesia ini telah membawa dampak yang baik terhadap perkembangan industri kreatif digital sehingga muncul usaha yang berbasis elektronik, yang sangat memudahkan [4].

Kementrian pariwisata \& ekonomi kreatif memberi dukungan pada upaya menumbuhkembangkan kreatifitas, inovasi serta meningkatkan ekonomi sub kreatif. Berkembangnya era ekonomi kreatif karena dukungan produk digital hal ini sejalan visi pemerintah pada saat revolusi industri empat (Industri 4.0) [5]. Pada penelitian ini, objek penelitian adalah Perusahaan Pertanian Agrobisnis (PPA) yang memproduksi buah-buahan Jeruk dan Jambu Kristal, yang produknya telah dijual di Sumatera selatan, Bengkulu, Jawa sampai ke Pulau Bali [6].

Perusahaan Pertanian Agrobisnis (PPA) sebagai sebuah jenis usaha baru, dalam perjalanannya agar tetap eksis harus mampu selalu berinovasi membuat produk atau hal baru sehingga perusahaan dapat terus berjalan apa lagi pada saat pandemik covid-19 saat ini membuat semua serba tidak pasti [7][9], apa bila produk yang sudah ada tidak laku buah cepat membusuk. Ditengah ketidakpastian dan resiko yang besar ini, sebagai perusahaan yang basis bisnisnya berada didaerah dan cukup jauh dengan pasar bagi produk yang dihasilkan semua hal yang dilakukan maka memerlukan perencanaan masa mendatang dengan pemikiran dan rencana strategis bisnis yang baik [8]. Faktanya tingkat kelangsungan hidup bagi perusahaan rintisan hanya 5\% pada 5 tahun pertama [10], hal ini disebabkan masih banyak dari pemilik usaha merasa bahwa perencanaan bukan hal yang terlalu penting dan pada saat aplikasi sangat sulit, tetapi hasil penelitian yang ada telah menunjukan fakta bahwa perusahaan skala kecil dan menengah yang mampu merumuskan strategi dan mengaplikasikannya ternyata lebih mampu dan unggul dari pesaingnya serta lebih tahan menghadapi permasalahan [11]. Penelitian ini, hasil akhirnya mengetahui kondisi internal dan kondisi eksternal perusahaan saat ini baik dari sisi bisnis maupun sisi teknologi dan sistem informasi serta bisnis, yang nantinya menjadi bahan evaluasi bagi Perusahaan PPA [12]. Artinya penelitian ini membantu manajemen tingkat atas PPA menyediakan rekomendasi strategi teknologi dan sistem informasi yang pastinya sejalan dengan strategi bisnis yang dijalankan Perusahaan Pertanian Agrobisnis (PPA) Pagar Alam. 


\section{METODE PENELITIAN}

Analisa dan rencana strategi teknologi \& sistem informasi (TSI) yang sesuai dengan kultur perusahaan tentu sangat bermanfaat dalam merancang aplikasi teknologi \& sistem informasi (TSI) yang mampu memberikan keunggulan kompetitif bagi perusahaan secara berkelanjutan [12]. Analisa dan perencanaan TSI yang disusun secara matang mampu mendukung visi, misi dan tujuan organisasi [13]. Pada penyusunan suatu rencana strategis yang unggul dibutuhkan metodologi yang juga sesuai dengan objek penelitian. Sangat dibutuhkan kerangka kerja dalam penelitian ini, maka peneliti dalam hal ini menggunakan kerangka kerja Ward Peppard, Ward Peppard dipilih karena paling sesuai dengan proses bisnis pada langkah bisnis yang dilakukan Perusahaan PPA karena mampu mencakup seluruh aspek penting organisasi perusahaan, seperti: strategis bisnis sekarang, aspek ekonomi, politik, sosial, iklim bersaing, kondisi TSI dari perspektif bisnis, kontribusi TSI pada bisnis, sumber daya manusia, insfrastruktur TSI, portofolio TSI sekarang, serta tren TSI [12][14]. Pada pelaksanaannya penelitian ini menggunakan metode deskriftif kualitatif, dimana metode ini dilakukan dengan mengumpulkan data kemudian diklasifikasi dan dianalisis agar didapatkan gambaran lengkap tentang objek penelitian, pada pelaksanaannya penelitian dilakukan dengan beberapa tahapan proses, yaitu:

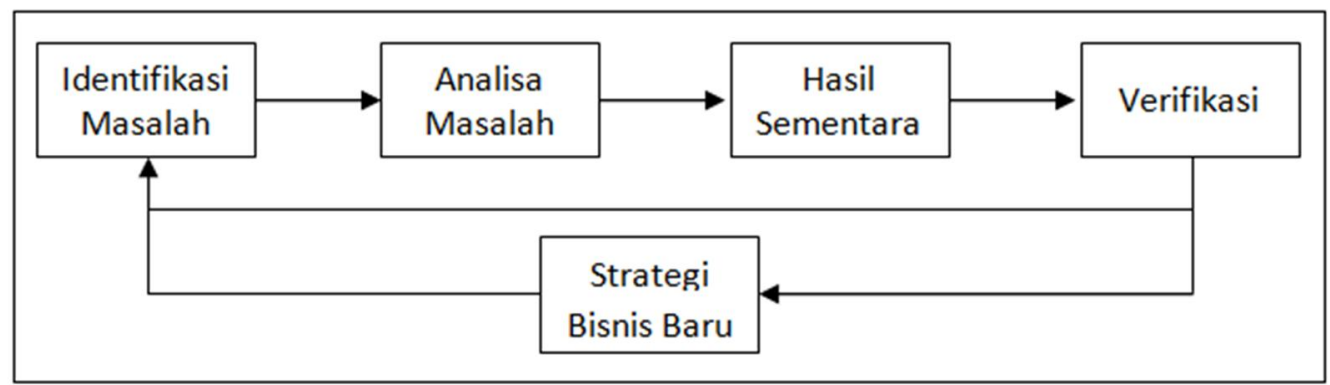

Gambar 1. Tahapan Penelitian

a. Tahap identifikasi, identifikasi terhadap: masalah, profil, tujuan, ruang lingkup, visi, misi secara langsung wawancara dengan manajemen PPA.

b. Tahap analisis internal dan eksternal TSI serta bisnis.

c. Tahap penentuan strategi TSI berdasarkan hasil analisis.

d. Tahap verifikasi hasil penelitian dengan diskusi dalam organisasi tujuannya mendapat koreksi hasil.

\section{HASIL \& PEMBAHASAN}

\section{A. Profil PPA Pagar Alam}

Perusahaan pertanian agrobisnis (PPA) Pagar Alam, merupakan perusahaan agrobisnis yang dibentuk oleh gabungan kelompok tani buah-buahan yang mengaplikasikan konsep agrobisnis, ide ini merupakan ide brilian yang dimunculkan oleh anak-anak pengelola usaha pertanian yang tergabung dalam kelompok tani itu, yang mana pada pengelolaan awalnya menggunakan konsep konvensional tradisional [6], wilayah pertaniannya terpisah-pisah dari Dempo utara, Pagar Alam Utara, sampai ke wilayah Tanjung Sakti Kab. Lahat. Ide penelitian ini muncul juga karena kondisi pandemic covid 19 yang dialami, ini melumpuhkan perekonomian dan kegiatan bisnis sehingga kelompok tani sulit memasarkan produk yang dihasilkan, yaitu buah-buahan. 


\section{B. Analisis Lingkungan Eksternal Bisnis PPA}

Pada tahap ini menjelaskan tentang situasi dan kondisi bisnis pada luar organisasi yang mana sarana analisis yang dipergunakan yaitu PEST-C, dimana berdasarkan hasil dari interview yang dilakukan terhadap narasumber utama (Manajemen puncak) PPA Pagar Alam [15], melalui alat analisis ini peneliti dapat melaksanakan pemetaan terhadap faktor-faktor eksternal dan hal apa saja yang berpengaruh terhadap kondisi bisnis organisasi dalam hal ini Perusahaan Pertanian Agrobisnis (PPA) Kota Pagar Alam, seperti ditampilkan pada Tabel Nomor 1.

Tabel 1. Faktor PEST-C Analisis

\begin{tabular}{|r|l|l|}
\hline No & \multicolumn{1}{|c|}{$\begin{array}{c}\text { Faktor } \\
\text { Analisis }\end{array}$} & \multicolumn{1}{c|}{ Pengaruhnya pada Organisasi PPA } \\
\hline 1. & Politic & $\begin{array}{l}\text { Sebenarnya faktor politik tak terlalu berpengaruh pada proses } \\
\text { kegiatan bisnis PPA, beberapa faktor berkaitan yaitu birokrasi dan } \\
\text { regulasi. }\end{array}$ \\
\hline 2. & Economic & $\begin{array}{l}\text { Arah perkembangan teknologi pertanian telah menumbuhkan iklim } \\
\text { bisnis positif saat pandemic, dan pandemic ini menjadi pengaruh } \\
\text { terjadinya krisis, serta ekonomi berpengaruh penting. }\end{array}$ \\
\hline 3. & Social & $\begin{array}{l}\text { Keadaan sosial mempengaruhi perkembangan industri pertanian seperti } \\
\text { kepercayaan konsumen terhadap hasil pertanian, budaya, minat dan } \\
\text { kebutuhan. }\end{array}$ \\
\hline 4. & Technology & $\begin{array}{l}\text { Pada industri pertanian teknologi rekayasa, teknologi penjualan sangat } \\
\text { penting untukkelangsungan proses bisnis. }\end{array}$ \\
\hline 5. & Competitor & $\begin{array}{l}\text { Perkembangan produk industri pertanian, makin menemukan persaingan } \\
\text { (produk/layanan). }\end{array}$ \\
\hline
\end{tabular}

Maka, sesuai dengan wawancara yang dilakukan pada narasumber, maka berikut hasil pemetaan PEST-C peluang dan ancamannya pada Tabel Nomor 2.

Tabel 2. Hasil Pemetaan PEST-C Analisis

\begin{tabular}{|c|c|c|c|}
\hline No & $\begin{array}{c}\text { Faktor } \\
\text { Analisis }\end{array}$ & Peluang & Ancaman \\
\hline \multirow[t]{2}{*}{1.} & \multirow[t]{2}{*}{ Politik } & $\begin{array}{l}\text { Pada industri pertanian aplikasi TSI } \\
\text { merupakan satu usaha di era pandemic } \\
\text { yang menuntut kreatifitas. }\end{array}$ & $\begin{array}{l}\text { Tidak saling integrasinya } \\
\text { pengurusan perijinan menjadi } \\
\text { kendala yang nyata. }\end{array}$ \\
\hline & & $\begin{array}{l}\text { Terdapat lembaga/instansi penyandang } \\
\text { dana yangmemberikan apresiasi bagi } \\
\text { pengusaha pertanian. }\end{array}$ & $\begin{array}{l}\text { Kendala birokrasi mengurus ijin } \\
\text { usahabaru. }\end{array}$ \\
\hline \multirow[t]{3}{*}{3.} & \multirow[t]{3}{*}{ Ekonomi } & $\begin{array}{l}\text { Perkembangan industri pertanian } \\
\text { berpengaruh baik bagi } \\
\text { perekonomiannya. }\end{array}$ & \multirow[t]{3}{*}{$\begin{array}{l}\text { Ada ancaman nyata akibat } \\
\text { pandemik daninvestasi asing. }\end{array}$} \\
\hline & & $\begin{array}{l}\text { Kemajuan \& kondusifnya iklim usaha } \\
\text { pertanian bisamenarik investor asing. }\end{array}$ & \\
\hline & & $\begin{array}{l}\text { Penjualan produk PPA dijual luar } \\
\text { daerah berdampak positif bagi } \\
\text { kesejahteraan. }\end{array}$ & \\
\hline \multirow[t]{2}{*}{4.} & \multirow[t]{2}{*}{ Sosial } & $\begin{array}{l}\text { Kepercayaan klien pada industri } \\
\text { rintisan teknologiyang semakin baik } \\
\text { dan kuat }\end{array}$ & \multirow[t]{2}{*}{$\begin{array}{l}\text { Adanya pemahaman masyarakat } \\
\text { usahapertanian tidak } \\
\text { menjanjikan. }\end{array}$} \\
\hline & & $\begin{array}{l}\text { Produk usaha pertanian sangat } \\
\text { dibutuhkan }\end{array}$ & \\
\hline
\end{tabular}

Buhori, et., al [Analisa Aplikasi Teknologi Informasi dan Strategi BisnisPerusahaan Agrobisnis] 


\begin{tabular}{|c|l|l|l|}
\hline 5. & Teknologi & $\begin{array}{l}\text { Kemajuan TSI pertanian } \\
\text { meningkatkan inovasi dan kreatifitas. }\end{array}$ & $\begin{array}{l}\text { Kemajuan TSI cepat } \\
\text { mengakibatkan perusahaan terlalu } \\
\text { adaptif. }\end{array}$ \\
\hline 6. & Kompetitor & $\begin{array}{l}\text { Kelompok tani menjadi komunitas } \\
\text { untuk menambahrelasi sehingga produk } \\
\text { makin dikenal. }\end{array}$ & $\begin{array}{l}\text { Usaha pertanian sejenis } \\
\text { menawarkanproduk lebih murah. }\end{array}$ \\
\cline { 3 - 4 } & & $\begin{array}{l}\text { Usaha pertanian menawarkan } \\
\text { produk lebih lengkap dan baik. }\end{array}$ \\
\cline { 3 - 4 } & & $\begin{array}{l}\text { Usaha pertanian sejenis } \\
\text { pemasaran lebihbaik. }\end{array}$ \\
\hline
\end{tabular}

C. Analisis Lingkungan Bisnis Internal PPA

Analisis lingkungan bisnis internal menggunakan SWOT dan value chain, SWOT untuk menganalisis organisasi[16], hasilnya dideskripsikan Tabel Nomor 3.

Tabel 3. Analisis SWOT

\begin{tabular}{|c|c|c|}
\hline & Opportunities & Threats \\
\hline & $\begin{array}{l}\text { Era ekonomi kreatif mendukung } \\
\text { pengembangan usaha berbasis TSI }\end{array}$ & Kurang pengalaman dari SDM \\
\hline & $\begin{array}{l}\text { Honor Pagar Alam tak terlalu } \\
\text { besar }\end{array}$ & $\begin{array}{l}\text { Ada pendapat usaha pengelola } \\
\text { dari luar lebih bagus }\end{array}$ \\
\hline & Mudah pengurusan modal di bank & Perubahan TSI sangat cepat \\
\hline & Kondisi persaingan usaha sehat & Kegiatan usaha lini bisnis sama \\
\hline Strengths & $S-O$ & $S-T$ \\
\hline $\begin{array}{l}\text { Pada operasional kantor } \\
\text { berada di Pagar Alam } \\
\text { yang mana operasional } \\
\text { murah, survival } \\
\text { perusahaan lebih } \\
\text { tinggi. }\end{array}$ & \multirow{4}{*}{$\begin{array}{l}\text { Meningkatkan intensitas } \\
\text { komunikasibisnis dengan } \\
\text { perusahaan lain. } \\
\text { - Meningkatkan kualitas dan } \\
\text { kuantitasproduk sesuai } \\
\text { kebutuhan pasar. } \\
\text { - Melakukan kerjasama } \\
\text { denganperusahaan sejenis. }\end{array}$} & \multirow[t]{4}{*}{$\begin{array}{l}\text { - Harus melakukan diferensias } \\
\text { pada produk. } \\
\text { - Harus meningkatkan kualitas } \\
\text { dan kuantitas produk agar } \\
\text { mendapatfinding dari investor. }\end{array}$} \\
\hline $\begin{array}{l}\text { Pengelola memiliki } \\
\text { mindset terus } \\
\text { berinovasi dan ide } \\
\text { kreatif. }\end{array}$ & & \\
\hline $\begin{array}{l}\text { Terus melaksanakan } \\
\text { riset kemauanpasar. }\end{array}$ & & \\
\hline $\begin{array}{l}\text { Produk kompetitif dan } \\
\text { stock banyak }\end{array}$ & & \\
\hline Weaknesses & $\mathrm{W}-\mathrm{O}$ & $W-T$ \\
\hline $\begin{array}{ll}\text { Terlalu } & \text { banyak } \\
& \text { produk } \\
& \text { usaha } \\
\text { pertanian dihasilkan, di }\end{array}$ & \multirow{3}{*}{$\begin{array}{l}\text { - Pemberian tugas terhadap tim } \\
\text { jelas, sehingga satu produk di } \\
\text { tangani satu tim } \\
\begin{array}{l}\text { Optimalisasi strategi pemasaran } \\
\text { suatu produk }\end{array}\end{array}$} & $\begin{array}{l}\text { Perbaikan seleksi SDM. } \\
\square \text { Melakukan pelatihan pegawai } \\
\square \text { Melakukan pelatihan terhadap } \\
\text { teknologi pertanian baru }\end{array}$ \\
\hline $\begin{array}{l}\text { produksibersama } \\
\text { membuat tidak fokus. }\end{array}$ & & Solusi: \\
\hline $\begin{array}{l}\text { Ada produk kurang } \\
\text { menghasilkan profit }\end{array}$ & & $\begin{array}{l}\text { Diperlukan sistem rekrutmen } \\
\text { berbasis teknologi digital (TSI). }\end{array}$ \\
\hline
\end{tabular}


Model bisnis berubah
Diperlukan pelatihan berbasis teknologi digital (TSI).

Berikutnya untuk analisis rantai bermanfaat untuk memetakan secara keseluruhan proses bisnis yang dilaksanakan pada PPA, yang mana aktivitas bisnis tersebut yaitu: desain, coding testing dan pemasaran, sebagai berikut:

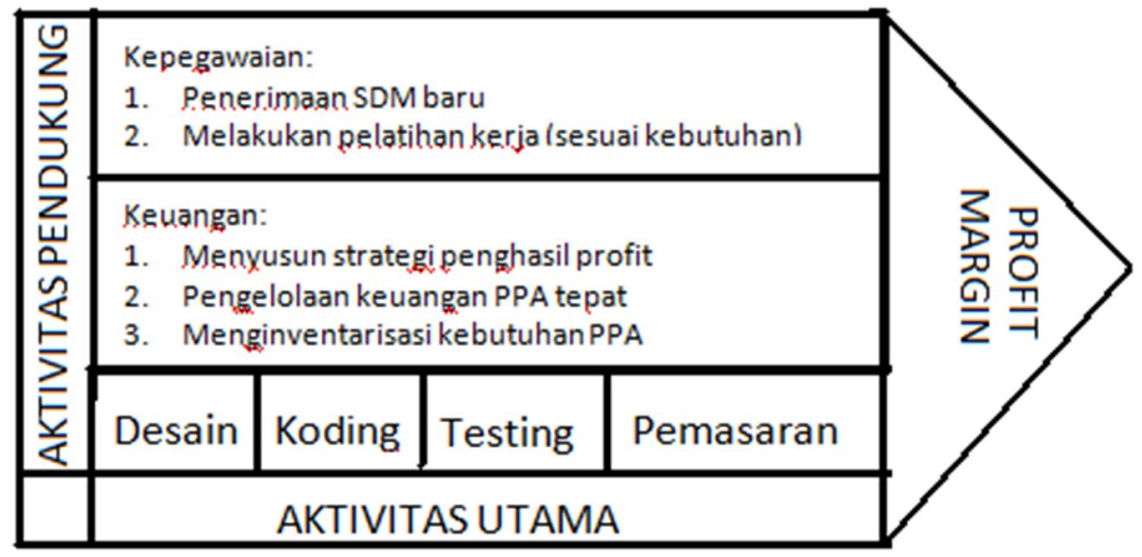

Gambar 2. Analisis Rantai Nilai PPA

Desain, Aktivitas pertama desain merupakan fase perencanaan sistem, sebuah kegiatan pendahuluan yang mana kegiatan yang dilakukan yaitu membuat deskripsi aplikasi yang dibangun, selain itu juga perkiraan anggaran yang dikeluarkan selama proses pengembangan aplikasi, serta perkiraan waktu yang diperlukan sehingga suatu aplikasi dapat dirilis. Pada sisi perencanaan ini juga dideskripsikan alur kerja sistem dalam bentuk flowchart, data flow diagram, entity relationship diagram.

Coding, merupakan aktivitas teknis, pembuatan UI mockup atau desain antarmuka aplikasi. Aktivitasnya meliputi pembuatan kerangka aplikasi dang menuangkan ide desain yang dilakukan sebelumnya dan mengkonversi kedalam bentuk source code (pemrograman).

Testing, merupakan kegiatan setelah implementasi aplikasi selesai, dengan pertimbangan UX \& UI maka dilaksanakan user acceptance testing (UAT). Testing kegiatan terakhir sebelum rilis.

Pemasaran, marketing atau service (jasa) perusahaan, merupakan tujuan memperoleh keuntungan, yang mana kegiatannya berupa strategi pengembangan pemasaran, riset pasar, kehumasan dan pencitraan.

\section{Analisis Lingkungan Eksternal TSI}

Pada analisis lingkungan eksternal TSI, dilakukan analisis tren TSI pada saat yang banyak digunakan pada industri teknologi pendukung pertanian [17], maka berdasarkan data dan informasi hasil observasi diperoleh kesimpulan terdapat beberapa tren teknologi dalam pengembangan industri pertanian, seperti:

1. Teknologi cloud computing.

Pada saat ini aplikasi cloud computing telah diaplikasikan pada berbagai keperluan, cloud merupakan sumber daya komputasi yang memiliki banyak sekali aplikasi dan data yang bisa diakses melalui jaringan internet. Artinya teknologi cloud ini pengguna dapat mengakses data atau aplikasi dimana pun selama terhubung internet, selain itu pengguna dapat juga menyimpan data, menghapus data dan mengelola data dimana pun. 
2. Scrum (Metode agile development).

Agile merupakan metode alternative pada manajemen proyek, untuk pengembangan perangkat lunak. Dengan agile developer menjadi alternative selain waterfall yang umum untuk pengembangan software. Agile memberikesempatan menilai arah proyek pada semua siklus software. Itu dicapai melalui irama kerja yang berulang, aspeknya pengembangan, desain, implementasi dan ditinjau secara terus menerus.

E. Analisis Lingkungan Internal TSI.

Kegiatan analisis dilaksanakan berdasarkan aset baru milik PPA, asset berupa software, hardware, dan SDM berhubungan langsung dengan TSI [21]. Daftar list asset TSI dan SDM [18], Tabel Nomor 4.

Tabel 4. Aset PPA

\begin{tabular}{|r|l|l|c|l|}
\hline No & \multicolumn{1}{|c|}{ Aset PPA } & \multicolumn{1}{|c|}{ Kondisi Aset } & Volume & \multicolumn{1}{|c|}{ Keterangan } \\
\hline 1 & Personal komputer & Baik & 2 & $\begin{array}{l}\text { PPA menyediakan PC } \\
\text { sebanyak 2 buah }\end{array}$ \\
\hline 2 & Printer & Baik & 1 & 2 buah \\
\hline 3 & LCD Proyektor & Baik & 1 & 2 buah \\
\hline 4 & SDM TSI & $\begin{array}{l}\text { Pendidikan minimal S1 } \\
\text { (Teknik Informatika, Ilkom) }\end{array}$ & 2 & $\begin{array}{l}\text { PPA memiliki 2 orang } \\
\text { SDM TSI }\end{array}$ \\
\hline
\end{tabular}

Keadaan infrastruktur milik PPA cukup memadai sesuai dengan kapasitas kerja organisasi perusahaan, misalnya bisa dilihat melalui Tabel Nomor 5 dan gambar 3 dibawah ini:

Tabel 5. Insfrastruktur TSI PPA

\begin{tabular}{|c|c|c|}
\hline No & Infrastruktur & Keterangan \\
\hline 1 & Fasilitas Internet & $\begin{array}{l}\text { ISP menggunakan indihome FO } 20 \mathrm{Mb}, 1 \text { buah } \\
\text { router, } 1 \text { buah router, mikrotik RB750 dan } 1 \text { buah } \\
\text { akses poin. } \\
\text { - Internet menggunakan wireless. }\end{array}$ \\
\hline 2 & Database Server & - Cloudserver: Digitalocean. \\
\hline 3 & Ruang Data Center & $\begin{array}{ll}\text { o } & \text { Tidak ada } \\
\end{array}$ \\
\hline 4 & $\begin{array}{l}\text { Rencana penanggulangan } \\
\text { bencana }\end{array}$ & ○ Tidak ada \\
\hline
\end{tabular}

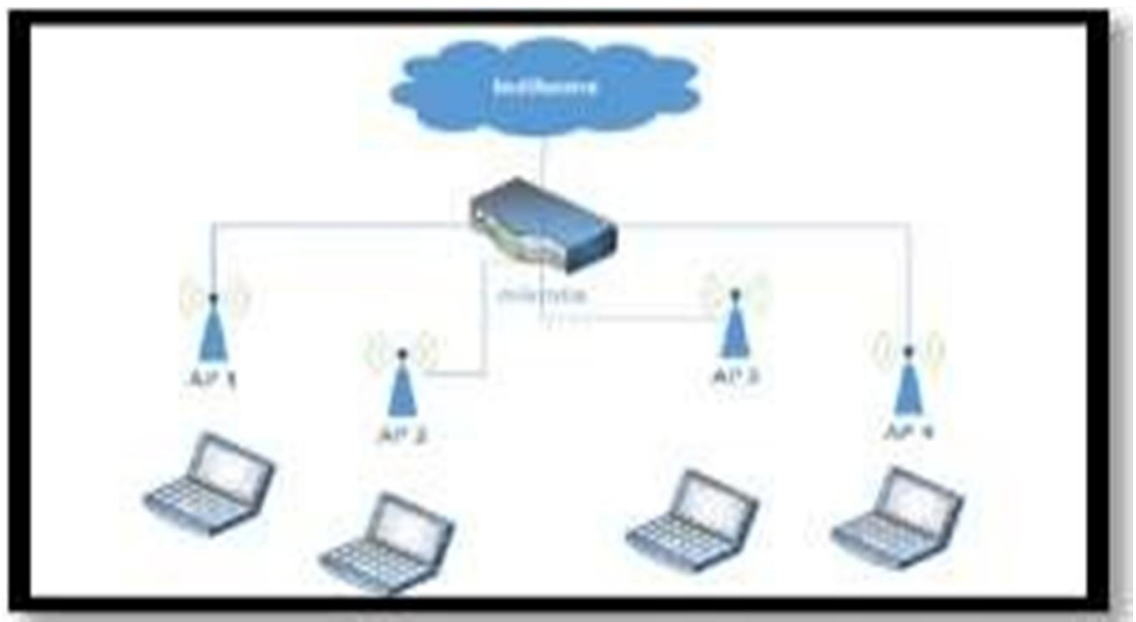

Gambar 3. Topologi Jaringan PPA 
Berikut merupakan beberapa aplikasi yang telah dimanfaatkan oleh PPA dalam mendukung seluruh aktivitas prosesbisnis yang administrative, pada Tabel Nomor 6.

Tabel 6. Administrasi SI PPA

\begin{tabular}{|c|l|l|l|}
\hline No & \multicolumn{1}{|c|}{ Bidang } & \multicolumn{1}{|c|}{ Jenis kegiatan } & SI yang diaplikasikan \\
\hline 1 & $\begin{array}{l}\text { Human resources \& General } \\
\text { affairs }\end{array}$ & Inventarisasi data pegawai & Google spreadsheet \\
\hline 2 & $\begin{array}{l}\text { Human resources \& General } \\
\text { affairs }\end{array}$ & Inventaris barang kantor & Google spreadsheet \\
\hline 3 & Finance & $\begin{array}{l}\text { Laporan data keuangan \& } \\
\text { pajak }\end{array}$ & $\begin{array}{l}\text { Google spreadsheet, } \\
\text { Aplikasi e-faktur }\end{array}$ \\
\hline 4 & General & Profile perusahaan & Website company profile \\
\hline
\end{tabular}

Maka sesuai dengan pemetaan portofolio pengembangan aplikasi dilakukan menggunakan McFarlan Grid sehingga didapatkan matriks portofolio sesuai Tabel 7, dibawah ini:

Tabel 7. Matriks Portofolio

\begin{tabular}{|l|l|}
\hline \multicolumn{1}{|c|}{ Strategic } & High potential \\
\hline Website company profile & - \\
\hline SI Kepegawaian PPA & - \\
SI Inventaris barang perusahaanSI Data keuangan & \\
\hline \multicolumn{1}{|c|}{ Key operational } & Support \\
\hline
\end{tabular}

Software yang dimanfaatkan PPA pada saat mendukung aktivitas proses bisnis teknis dan berkaitan denganpengembangan software, ditunjukan Tabel Nomor 8.

Tabel 8. SI Engineering PPA

\begin{tabular}{|c|l|l|}
\hline No & \multicolumn{1}{|c|}{ Kegiatan } & \multicolumn{1}{|c|}{ Software yang diaplikasikan } \\
\hline 1 & Pengembangan sistem TSI & $\begin{array}{l}\text { - Web apps: PHP, Lavarel. } \\
\text { - Mobile app: Java, android studio, } \\
\text { android SDK, androidemulator, } \\
\text { objective-C, } \text { swift, xcode, simulator. }\end{array}$ \\
\hline 2 & Penyimpanan resource code & Git \\
\hline 3 & $\begin{array}{l}\text { Dokumentasi penyimpanan } \\
\text { pengembangan } \\
\text { sistem }\end{array}$ & Scrum tools \\
\hline 4 & User acceptance testing (UAT) process & Google analytics, scrum tools, tes flight. \\
\hline 5 & Publish process & $\begin{array}{l}\text { i-tunes connect, scrum tools, play store } \\
\text { publish. }\end{array}$ \\
\hline 6 & Proses monitoring & Google analytics. \\
\hline 7 & Updating process & i-tunes connect, play store publish. \\
\hline
\end{tabular}

F. Menentukan strategi TSI-Business.

Perusahaan pertanian agrobisnis (PPA) Pagar Alam sangat menyadari ditengah pandemic ini, maka pemanfaatan TSI menjadi bagian core business perusahaan. Yang mana penentuan strategi TSI ini diperlukan supaya organisasi mampu mengaplikasikan TSI agar hasil dari investasi TSI ini maksimal [19]. Selain itu rencana strategi yang optimal juga mampu mendukung kegiatan bisnis perusahaan dan menciptakan keunggulan kompetitifperusahaan saat menjalankan usaha. 
Tabel 9. Menentukan Strategi TSI-Business.

\begin{tabular}{|c|l|l|l|}
\hline No & \multicolumn{1}{|c|}{ Strategy (Objectives) } & \multicolumn{1}{|c|}{ Action (CSF) } & Rekomendasi TSI \\
\hline Perspektif customers & Mengukur pangsa pasar & $\begin{array}{l}\text { Adanya sistem untuk ketahui } \\
\text { prospek } \\
\text { pangsa pasar. }\end{array}$ & SI Riset pasar \\
\hline 2 & $\begin{array}{l}\text { Mengukur pertumbuhan } \\
\text { customers }\end{array}$ & $\begin{array}{l}\text { Adanya sistem pengelola } \\
\text { peningkatanjumlah customer. }\end{array}$ & Google analytics \\
\hline 3 & $\begin{array}{l}\text { Mengukur kepuasan } \\
\text { customers }\end{array}$ & $\begin{array}{l}\text { Adanya sistem merecord } \\
\text { kepuasan } \\
\text { kepada produk }\end{array}$ & $\begin{array}{l}\text { SI Integrasi review } \\
\text { customers } \\
\text { Rating+review play } \\
\text { stores) }\end{array}$ \\
\hline 4 & $\begin{array}{l}\text { Indentifikasi } \\
\text { peningkatanpendapatan }\end{array}$ & $\begin{array}{l}\text { Adanya sistem penghitung } \\
\text { pertumbuhanpendapatan }\end{array}$ & $\begin{array}{l}\text { SI Accounting } \\
\text { (keuangan) }\end{array}$ \\
\hline 5 & $\begin{array}{l}\text { Sistem inventaris asset } \\
\text { Perspektif financials }\end{array}$ & $\begin{array}{l}\text { Adanya sistem pengelolaan } \\
\text { asset PPA }\end{array}$ & \begin{tabular}{l} 
SI Pengelolaan asset PPA \\
\hline Perspektif internal business
\end{tabular} \\
\hline 6 & $\begin{array}{l}\text { Kegiatan operasional } \\
\text { pengembangan }\end{array}$ & $\begin{array}{l}\text { Optimalisasi tools atau service } \\
\text { yang ada }\end{array}$ & $\begin{array}{l}\text { Optimalisasi aplikasi } \\
\text { tools } \\
\text { tersedia sesuai kebutuhan } \\
\text { pengembangan produk } \\
\text { PPA }\end{array}$ \\
\hline 7 & $\begin{array}{l}\text { Evaluasi \& monitoring } \\
\text { (Monev) }\end{array}$ & $\begin{array}{l}\text { Ada sistem penilai } \\
\text { produktivitas SDM }\end{array}$ & $\begin{array}{l}\text { Mengaplikasikan tools, } \\
\text { missal: Github dan } \\
\text { bitbucket. }\end{array}$ \\
\hline
\end{tabular}

Berikutnya berdasarkan analisa lingkungan internal TSI yang dilaksanakan telah diperoleh beberapa solusi perencanaan TSI yang bisa diaplikasikan dan dikembangkan sesuai keperluan PPA pada masa mendatang.

Tabel 10. Identifikasi Solusi TSI

\begin{tabular}{|l|l|l|l|}
\hline \multicolumn{1}{|c|}{ Bidang } & \multicolumn{1}{|c|}{ Tujuan } & \multicolumn{1}{c|}{ Keterangan } & \multicolumn{1}{|c|}{ Solusi SI } \\
\hline $\begin{array}{l}\text { Human } \\
\text { resource } \\
\text { general affairs }\end{array}$ & Rekrutmen & Proses rekrutmen pegawai & SI Kepegawaian \\
\cline { 2 - 3 } & Biodata pegawai & $\begin{array}{l}\text { Informasi pegawai (Nama, } \\
\text { kelamin, TTL, dll) }\end{array}$ & \\
\cline { 2 - 3 } & $\begin{array}{l}\text { Penggajian } \\
\text { pegawai }\end{array}$ & $\begin{array}{l}\text { Pendataan masa kerja, jabatan } \\
\text { dan bonus }\end{array}$ & \\
\hline Finance & $\begin{array}{l}\text { Laporan keuangan } \\
\text { bulanan }\end{array}$ & $\begin{array}{l}\text { Penjelasan pengeluaran dan } \\
\text { pendapatan operasional bulanan }\end{array}$ & SI Keuangan \\
\cline { 2 - 4 } & Laporan pajak PPA & $\begin{array}{l}\text { Kewajiban pajak \& pertambahan } \\
\text { nilai }\end{array}$ & $\begin{array}{l}\text { SI (Aplikasi) } \\
\text { e-faktur }\end{array}$ \\
\hline Marketing & Pemasaran produk & $\begin{array}{l}\text { Tata cara promosi \& event } \\
\text { promosi }\end{array}$ & $\begin{array}{l}\text { Sosial media: } \\
\text { Facebook, tweet, } \\
\text { sponsor, linkedIn. }\end{array}$ \\
\hline $\begin{array}{l}\text { Inventaris } \\
\text { PPA }\end{array}$ & $\begin{array}{l}\text { Pendataan asset } \\
\text { PPA }\end{array}$ & Inventarisasi barang PPA & SI Inventaris \\
\hline
\end{tabular}




\section{G. Portfolio aplikasi mendatang PPA}

Hasil dari analisis serta identifikasi terhadap seluruh kebutuhan PPA, berikut ini merupakan solusi keperluan yang dipetakan oleh matrik portfolio McFarlan menunjukan kesimpulan analisis keseluruhan software pendukung aktivitas proses bisnis administrasi PPA Pagar Alam.

Tabel 11. Portofolio Aplikasi Mendatang (Usulan)

\begin{tabular}{|l|l|l|l|}
\hline \multicolumn{2}{|c|}{ Strategic } & \multicolumn{2}{c|}{ High Potential } \\
\hline Website PPA & Ada & SI Marketing & Baru \\
\hline Sistem pemasaran & Upgrade & SI Review Rating & Baru \\
\hline \multicolumn{2}{|c|}{ Key Operational } & \multicolumn{2}{c|}{ Support } \\
\hline SI Kepegawaian & Baru & SI e-Factur & Baru \\
\hline SI Accounting & Baru & SI e-Recruitment & Baru \\
\hline SI -Training & Baru & \multicolumn{1}{c}{} \\
\hline
\end{tabular}

H. Menentukan strategi TSI PPA

Maka berdasarkan hasil dari analisis yang dilakukan, berikut ini merupakan strategi teknologi dan sistem informasi (TSI) PPA Pagar Alam:

i. Mengaplikasikan cloud computing.

Aplikasi cloud computing saat ini mirip dengan aplikasi layanan berbasis internet untuk proses bisnis pada organisasi PPA, apa lagi jika diaplikasikan pada perusahaan skala belum terlalu besar atau Small medium enterprise (SME) aplikasi cloud computing, di prediksi dari hasil analisis mampu memberikan manfaat dan efisiensi, dalam hal misalnya dalam memangkas biaya operasional, sehingga biaya operasional bisa dialihkan untuk pengembangan bisnis, selain itu aplikasi teknologi cloud ini juga bisa diaplikasikan sebagai solusi atas antisipasi kesalahan. Cloud computing mampu mengurangi keperluan pusat data, insfrastruktur dan sumber daya TSI [17], terdapat tiga jenis layanan cloud computing dapat dimanfaatkan PPA:

1. Software as a service (SaaS).

Aplikasi layanan SaaS PPA tidak harus mengeluarkan investasi in house development dan lisensi, yang mana pengguna SaaS hanya perlu menggunakan aplikasi tidak perlu bagaimana data disimpan dan melakukan maintenance, dalam hal ini pembayaran hanya berdasarkan pemakaian saja missal aplikasi CRMdan google docs.

2. Platform as a service (PaaS).

Metode pelayanan PaaS pada saat aplikasi yang disediakan SaaS tidak sesuai keperluan proses bisnis pada PPA, dengan PaaS pengguna bisa membangun aplikasi, upload aplikasi, melakukan testing, maupun mengatur konfigurasi, pengguna yang memakai SaaS dan PaaS tak memiliki kontrol terhadap sumber daya komputasi seperti: memory, prosessing power \& sebagainya. Misalnya PaaS ialah google (web application platform) yang menyediakan API untuk developer untuk membangun aplikasi web, dan aplikasi CRM yang disediakan bagi perusahaan yang memerlukan.

3. Infrastruktur as a service (IaaS).

Jika SaaS dan PaaS tak terlalu berfungsi bagi PPA, IaaS sangat menguntungkan jika diaplikasikan pada perusahaan kecil, yang masih memerlukan perbaikan dari infrastruktur TSI nya, tanpa harus membeli perangkat yang diperlukan, missal dari IaaS adalah Amazon VPC.

ii. Usulan aplikasi teknologi Scrum.

Aplikasi scrum ini sebuah proses bersifat agile, saat menangani produk yang komplek, scrum mempunyai proses berulang, iterative dan bertahap pada saat menangani ketidakpastian proses pengembangan produk PPA. Terdapat tiga peran dalam proses scrum, yaitu: development team, product owner dan scrum master. Development team merupakan 
tim pengembang yang melakukan pembuatan produk. Pada software tim pengembang ini memberi peningkatan software secara bertahap [20]. Dimana anggota tim pengembang tersusun dari software developer, designer, business analysist dan tester. Sedangkan scrum master merupakan individu yang membantu tim dalam membuat produk pada proses scrum. Pihak ini yang bisa memastikan praktik, nilai, dan aturan dalam scrum diaplikasikan secara tepat, membantu memfasilitiasi keputusan development team yang self organizing. Dimana produk owner merupakan individu yang hapal nilai produk yang dibangun dan memaksimalkannya dalam kerja dengan tim pengembang. Produk owner menjelaskan visi produk pada development team, mengapa suatu produk dibuat dan apa nilai yang diberikan produk tersebut.

iii. Menentukan strategi manajemen TSI.

Pada upaya menyesuaikan keselarasan strategi bisnis dan TSI dibutuhkan perencanaan strategi TSI sejalan dengan visi, misi dan tujuan PPA, yang mana rumusan rekomendasi ini dideskripsikan Tabel 12.

Tabel 12. Rumusan Strategi Manajemen TSI pada Prespektif SAMM

\begin{tabular}{|c|l|l|}
\hline No & \multicolumn{1}{|c|}{ Kriteria } & \multicolumn{1}{c|}{ Rekomendasi } \\
\hline 1 & Communications & $\begin{array}{l}\text { Harus ada weekly atau daily meeting yang melibatkan unit bisnis } \\
\text { dan unit TSI }\end{array}$ \\
\hline 2 & $\begin{array}{l}\text { Competency atau } \\
\text { value measurements }\end{array}$ & $\begin{array}{l}\text { Menentukan KPI yang tepat/jelas dan bisa dipahami oleh tiap } \\
\text { unit, evaluasi harusdilakukan secara rutin dan melibatkan } \\
\text { mitra/investor. }\end{array}$ \\
\hline 3 & Governance & $\begin{array}{l}\text { Harus tersusun rencana strategis TSI yang melibatkan semua } \\
\text { elemen agar } \\
\text { berperan pada keberhasilan PPA }\end{array}$ \\
\hline 4 & Partnership & $\begin{array}{l}\text { Harus disusun standar resiko dan insentif yang adil, reward, } \\
\text { program kolaborasiTSI dan bisnis missal weekly atau monthly } \\
\text { meeting }\end{array}$ \\
\hline 5 & Scope \& architecture & $\begin{array}{l}\text { Harus dibuat standar pencatatan inventory hardware dan } \\
\text { software }\end{array}$ \\
\hline 6 & Skills & $\begin{array}{l}\text { Pembuat keputusan sebaiknya melibatkan seluruh elemen PPA, } \\
\text { harus adapembentukan program yang bisa mengantisipasi } \\
\text { perubahan }\end{array}$ \\
\hline
\end{tabular}

iv. Verifikasi hasil penelitian

Pada tahapan untuk dilakukan untuk mendapatkan masukan atas strategi perencanaan yang telah disusun, verifikasi dilaksanakan dengan mengirim dokumen hasil penelitian pada beberapa subjek penelitian, seperti $C E O, C T O$ dan project manager PPA sebagai objek penelitian. Selain itu, peneliti juha meminta masukan dari anggota kelompok tani sebagai pihak eksternal PPA, juga penggiat dari usaha ini, terdapat beberapa masukan dirangkum, terdeskripsi pada uraian dibawah:

a. Usulan aplikasi layanan cloud computing mendukung proses bisnis PPA lebih baik menggunakan jenisinsfrastruktur IaaS sebab fasilitas yang diberikan lebih lengkap dan lebih bermanfaat.

b. Pengusulan aplikasi e-Recruitment dan e-Trainning sangat diperlukan bagi PPA, adanya otomatisasi ke dua proses akan memudahkan PPA mencari dan mengembangkan bakat terbaik perusahaan.

c. PPA Pagar Alam merupakan perusahaan pertanian yang masih terus mencari model bisnis, dan fokus pengembangan produk agar dapat terus bertahan di pasar, sebab itu service (layanan) merupakan solusi. 


\section{KESIMPULAN}

Sesuai dengan hasil dari analisa dan pembahasan rencana strategi TSI pada PPA Pagar Alam, bisa ditarik kesimpulan bahwa. Pertama, menentukan strategi TSI yang bisa menghasilkan usulan aplikasi bersifat strategis dihasilkan melalui perbaikan profil perusahaan, penggunaan aplikasi digital marketing dan dari penelitian didapat yang bersifat key operational (SI Kepegawaian, SI Accounting, e-Training), bersifat high potensial (SI Marketing, SI Review dan rating produk), yang bersifat support (e-Recritment, SI e-Factur). Kedua, menentukan strategi TSI yang menghasilkan usulan aplikasi cloud computing pada tiap proses bisnis PPA dan aplikasi scrum pada pengembangan software. Ketiga, menentukan strategi manajemen TSI yang menghasilkan daftar aktifitas bisnis yang membatu PPA meningkatkan keselarasan strategi bisnis dan TSI untuk mencapai keunggulan kompetitif PPA, yang mana usulan kegiatan dibuat berdasarkan teori kematangan keselarasan berisi enam kriteria utama. Keempat, berdasarkan FGD, PPA menyetujui dan menerima hasil penelitian, yaitu rekomendasi aktifitas bisnis berdasarkan enam kriteria yaitu: komunikasi, kompetensi, tata kelola, kerjasama, arsitektur dan keahlian.

\section{SARAN}

Berdasarkan hasil penelitian yang dilakukan pada PPA Pagar Alam, dari kesimpulan yang diperoleh makapeneliti memberikan sarana:

a. Usulan TSI bagi jenis usaha yang lain maka akan mengalami perbedaan dengan hasil yang didapatdari perusahaan pertanian ini.

b. Penggunaan data minning akan menghasilkan aplikasi yang lebih bagus dan aplikatif.

\section{DAFTAR PUSTAKA}

[1] Muslim, B. 2017, Pengantar Teknologi Informasi, CV. Budi Utama (Deepublish), Yogyakarta.

[2] Kominfo. 2018, Infografis Penetrasi dan Prilaku Pengguna Internet Indonesia, [Online]. Available https://web.kominfo.go.id/sites/default/files/Laporan\%20Survei\%20APJII_2017_v1.3.pdf

[3] Muslim, B. 2018, Analisis Sistem Informasi (SI) Terintegrasi di Perguruan Tinggi (PT) (Studi Kasus: STT Pagaralam), Jurnal Teknologi Informasi MURA, Vol 10. Page 83-91.

[4] Asmawati, et., al. 2020, Implementasi Media E-Commerce pada Pemasaran Kain Sutra Mandar Di Polewali Mandar, Jatisi. Vol. 7, No. 3, Desember 2020, Hal. 408-415.

[5] Badan Ekonomi Kreatif. 2018, Bantuan Pemerintah untuk Revitalisasi Infrastruktur Fisik Ruang Kreatif, Sarana Ruang Kreatif, dan Teknologi Informasi dan Komunikasi, [Online]. Available: https://banper.bekraf.go.id

[6] Datika, W. et., al. 2018, Motivasi Membangun Kebun Jeruk Keprok RGL (Rimau Gerga Lebong) di Kelurahan Agung Lawangan Kecamatan Dempo Utara Kota Pagar Alam (Studi Kasus Sidarhan Pemilik Kebun Jeruk Keprok RGL), SOCIETA Vol. VII, No. 1, pp $40-50$. 
[7] Muslim, B. et.,al. 2014, Analisis Rencana Aplikasi Teknologi Informasi pada STT Pagaralam, Proseding Semnastik \& Magma, Palembang 23 Agustus. Pp 388-396.

[8] Muslim, B. 2017, Infrastruktur e-Business Sekolah Tinggi di Pagar Alam. Betrik, Vol. 11, No. 01pp. 53-60.

[9] Vargo, J. et., al. 2011, Crisis Strategic Planning for SMEs: Finding the Silver Lining, 49(18), $1-18$.

[10] Blank, Steve. 2013, Why The Lean Start-Up Changes Everything, Harvard Business Review.

[11] Kurniawan, N. B. et., al. 2013, Enterprise Architecture Design for Ensuring Strategic Business IT Alignment (Integrating SAMM with TOGAF 9.1), 2013 Joint International Conference on Rural Information \& Communication Technology and Electric-Vehicle Technology (rICT \& ICeV-T), 1-7.doi:10.1109/rICT-ICeVT.2013.6741505

[12] Papp, R. 2001, Strategic Information Technology: Opportunities for Competitive Advantage (pp. 1-24), Hershey PA.

[13] Ward. John, et., al. 2002, Strategic Planning For Information Systems 2nd Ed, John Wiley \& Sons, New York.

[14] Bullen, C. et.al. 1981, A Primer On Critical Success Factors, Christine V. Bullen John F. Rockart.

[15] Ward, John., et., al. 2003, Strategic Planning For Information Systems 2nd Ed. John Wiley \& Sons, Chicester.

[16] Gupta, A., et., al. 2013, Environment \& PEST Analysis: An Approach to External Business Environment, 2(1), 34-43.

[17] Humphrey, S. A. 2005, "SWOT Analysis for Management Consulting”, SRI Alumni Association Newsletter, December.

[18] Porter, M. E. 1985, The Competitive Advantage: Creating and Sustaining Superior Performance, NY: Free Press.

[19] Emet, G. 2017, SWOT Analysis: A Theoretical Review, 6-11, The Journal of International Social Research.

[20] Cash, J.I., et., al. 1988, Corporate Information Systems Management: Text and Cases, (2nd Ed.), Richard D. Irwin Inc.: Homewood, IL.

[21] Alex. 2021, Apa Itu Cloud Computing? [Online]. Available: http://www.cloudindonesia.or.id/apa-itu-cloud-computing.html.

[22] Muslim, B. 2018, Quantitative Risk Analysis of Asset Information Technology at STT Pagaralam, Senatik 2018. Jilid 1. Hal. 501-509. 